\title{
Cotidiano, GÊNERO, DistinçÃo - entrevista com Elizabeth Silva ${ }^{1}$
}

\author{
Michel Nicolau Netto (entrevistador)*
}

Contexto da entrevista: Esta entrevista se deu no Instituto de Filosofia e Ciências Humanas, da Unicamp, no dia 06/12/2018. Entre os dias 4 e 6 de dezembro ocorria o III Encontro do GEBU (Grupo de Estudos em Bourdieu da Unicamp), organizado por mim e por alunos e alunas de graduação e pós-graduação ${ }^{2}$ em Sociologia. Com apoio da FAPESP e do Programa de Pós-Graduação em Sociologia, recebemos a Professora Elizabeth Silva, inicialmente para fazer a Conferência de Encerramento. Ela, contudo, não apenas proferiu a conferência, entitulada "Habitus: arqueologia e mudanças", como generosamente participou de diversas atividades do encontro. Ao fim do evento, me honrou com uma entrevista de mais de uma hora. O leitor tem em mãos uma edição dessa entrevista. Sua versão mais extensa pode ser acessada no link a seguir: https://www.youtube.com/watch?v=FGUnKlbYbQs.

Apresentação da entrevistada: Elizabeth Bortolaia Silva é Professora Emérita em Sociologia na Open University (Reino Unido). Formada em Ciências Sociais pela Universidade de São Paulo, com mestrado em Ciência Política pela mesma universidade, fez seu doutorado no Departament of Social and Economic Studies, do Imperial College of Science and Technology da University of London (1988). Após breve retorno ao Brasil (1988 - 1990), quando foi professora-assistente na Unicamp, Elizabeth Silva trabalhou em diversas instituições nos Estados Unidos e Inglaterra: Harvard University (EUA), Brown University (EUA), University

\footnotetext{
UNICAMP - Universidade Estadual de Campinas, Instituto de Filosofia e Ciências Humanas. Campinas - SP - Brazil. 13081970 - michelnicolau@gmail.com. https://orcid.org/0000-0003-0893-971X. 1 Transcrição: Débaro Elida Chaves Silva e Marco Brefe.

2 São os seguintes alunos responsáveis pela organização desse encontro: Ana Clara Sapienci de Souza (mestranda), Bárbara Venturini Ábile (mestranda), Carolina Assumpção (mestranda), Juliana Closel Miraldi (doutoranda), Luã Ferreira Leal (doutorando). Mariana Martinelli (mestranda). Talitha Ferreira (doutoranda), Gustavo de Sousa Vieira (graduando), João Fernando Vieira Santos (graduando), Catharina De Angelo (graduanda).
} 
of Leeds (Inglaterra) e Open University (Inglaterra). Nessa última (1998-2018) Elizabeth Silva foi professora titular e se aposentou, em 2018, com o titulo de Professora Emérita. Ela é autora e organizadora de mais de uma dezena de livros e revistas academicas, além de ter publicado numerosos artigos e capítulos de livros. Entre suas publicações em livro mais relevantes estão Technology, Culture, Family: influences on home life (Palgrave, 2010) e a co-autoria do livro Culture, Class, Distinction (com Tony Bennett, Mike Savage, Alan Warde, Modesto Gayo-Cal e David Wright, 2009). Elizabeth Silva foi diretora do Centre for Citizenship, Identity and Governance (CCIG) na Open University. Seus interesses de pesquisa estão nas áreas de sociologia e cultura, desenvolvendo, atualmente, o projeto de pesquisa "Exhibiting Social Change", que se baseia nos engajamentos das artes visuais nas narrativas da violência da ditadura militar no Brasil e na imaginação para o futuro.

Apresentação do entrevistador: Michel Nicolau Netto é Professor do Departamento de Sociologia do Instituto de Filosofia e Ciências Humanas - Unicamp. É membro do Grupo de Estudos de Práticas Culturais Contemporâneas - GEPRACC e do Grupo de Estudos em Pierre Bourdieu - GEBU, Unicamp. Seu mais recente livro se chama Do Brasil e Outras Marcas: nação e economia simbólica nos megaeventos (Intermeios/FAPESP, 2019).

\section{$* * *$}

\section{Michel Nicolau:}

Como você começou a trabalhar com a obra de Pierre Bourdieu? Sei que você começou a ler A Distinção (2011) assim que ela foi lançada. Conta um pouco.

\section{Elizabeth Silva:}

Foi. Eu trabalhava no DIEESE [Departamento Intersindical de Estatística e Estudos Socioeconômicos], na verdade. Foi José Sérgio Leite Lopes ${ }^{3}$, que tinha estudado com Bourdieu na França, [quem me apresentou]. Na verdade eu li A Distinção pela primeira vez em francês. Eu morava no Rio de Janeiro, estava instalando o escritório regional do DIEESE no Rio, na época, e foi aí que comecei a ler $A$ Distinção. Eu me lembro que a gente brincava muito com as "questões de distinções", que era um conceito muito interessante e novo na época; mas eu não continuei trabalhando com [a obra de] Bourdieu. Eu li o Bourdieu nessa época, que deve ter sido entre 1980 e 1982 - foi publicado em 1979, na França. É, foi por aí. Foi logo...

3 Antropólogo, professor titular do Departamento de Antropologia do Museu Nacional da UFRJ. 
Michel Nicolau:

Antes da tradução inglesa?

\section{Elizabeth Silva:}

Antes da tradução inglesa, que foi publicada em 1984. Mas não trabalhei então com [a obra de] Bourdieu. Depois de eu terminar minha tese de doutorado ${ }^{4}$, na Inglaterra, eu fui morar nos Estados Unidos, onde eu comecei a me interessar por questões de gênero. "Divisão social" entrou para mim com "questão de gênero" - antes de "classe". Então "gênero e tecnologia". Eu continuei e continuo muito interessada em tecnologia, em termos da materialidade da vida social. Então eu comecei a trabalhar com tecnologia doméstica; eu mudei da "tecnologia automotiva" (Silva, 1991) para a "tecnologia doméstica" (Silva, 2010). Porque - é interessante - eu acho que meus interesses intelectuais sempre têm acompanhado as minhas mudanças de vida pessoal. Meu pai era apaixonado por mecânica mecânica automobilística, mecânica de carro. Quando ele me deu meu primeiro fusquinha, ele me ensinou tudo sobre o motor do fusquinha; o que, na verdade, foi muito importante para mim, na minha tese de doutorado: eu tinha uma familiaridade com tecnologia automotiva que me ajudou muito na tese. E depois eu fui estudar tecnologia doméstica. Eu morava num apartamento em Boston, Massachusetts, que tinha sido desenhado por uma feminista. Foi a primeira vez que eu vi um waste disposal - um dispositivo de lixo -, e a cozinha era desenhada de uma maneira fantástica.

Então... esse apartamento desenhado por uma feminista me estimulou muito em termos da facilidade do trabalho, e eu descobri o livro da Ruth Schwartz Cowan - More Work for Mother (1989) -, que é uma discussão de quatrocentos anos de inovação tecnológica doméstica. E eu achei fascinante tudo isso, e, ao mesmo tempo, eu estava me tornando mãe. Então a vida doméstica, a maternidade e todas essas questões me levaram a querer estudar mais a questão de gênero e a questão da tecnologia a serviço do cotidiano. E, depois disso, quando eu mudei de novo para a Inglaterra, já na universidade de Leeds, eu tive um financiamento do ESRC [Economic and Social Research Council, da Inglaterra] para fazer um projeto sobre tecnologias domésticas. Fiz esse projeto e estudei aí maternidade e família. Eu tenho dois livros nessa área: um que se chama Good Enough Mothering?, publicado em 1996, e outro, The New Family?, publicado em 1998 [com Carol Smart]. Então, como eu te falei, os temas de interesse vão acompanhando a biografia, de uma certa forma. E, a partir daí, eu comecei a me interessar por vida cotidiana. E, nessa época,

4 Silva, Elizabeth. "Labour and Technology in the Car Industry. Ford strategies in Britain and Brazil", University of London, 1988. 
o Stuart Hall, que era chefe do departamento de sociologia da Open University, se aposentou, e o Tony Bennett virou chefe de departamento na Open University. E o Tony me contratou. Com o meu interesse em vida cotidiana e divisão social, a partir disso é que eu comecei a trabalhar na Open University. Isso já era 1998, 1999.

E aí o Tony tinha feito um estudo que era uma réplica d'A Distinção na Austrália, que resultou no livro Accounting for Tastes [em co-edição com Michael Emmison e John Frow (1999)]. E o Tony queria fazer esse estudo na Inglaterra; e aí é que entra o Bourdieu de uma maneira muito séria na minha carreira acadêmica - é a partir daí. Porque nós fizemos esse pedido de financiamento, nós convidamos Mike Savage e Alan Warde para se juntarem a nós nesse projeto; e nós quatro fizemos o pedido, sob liderança do Tony, para o ESRC desse financiamento. E tivemos muita sorte em ter obtido esse financiamento. Foi o que se chama de large grant, foi muita grana, por três anos - de 2003 a 2006. Essas coisas todas demoram muito tempo. Você vê: você começa a pensar no projeto, você submete, aí você espera o resultado, aí você começa a fazer o projeto...

Esses projetos foram muito importantes, tanto no contexto inglês, como dentro de estudos "bourdieusianos" internacionalmente, porque a gente fez muita ligação com gente de todo o campo para fazer o trabalho. O livro, CCD (Culture, Class, Distinction (2009)), foi publicado no Japão nesse ano (2018). A edição é lindíssima. É preciosa. E abre e você lê, como um livro japonês, ao contrário - do fim para o começo. Eles fizeram uma tradução muito bonita - como obra, como materialidade do livro. Muito legal.

Michel Nicolau: E nesse livro vocês, a partir das pesquisas empíricas no Reino Unido, acabam revisitando, não só metodologicamente, mas também as categorias do Bourdieu. Talvez uma questão central que está colocada ali é a questão do capital cultural, habitus... Se você pudesse destacar algumas, digamos, possibilidades de rever a obra de Bourdieu a partir desse livro...

Elizabeth Silva: A gente realmente... Foi o que a gente fez. Era a proposta do $\mathrm{CCSE}^{5}$ [Cultural Capital and Social Exclusion] de revisitar A Distinção quarenta anos depois de quando o Bourdieu fez a pesquisa empírica e num outro espaço nacional. Então, tinham questões que, claro, eram contemporâneas, que o Bourdieu não analisou e que nós queríamos analisar. Por exemplo: questão de gênero, de etnia e a questão do espaço internacional e a influência desse nos espaços nacionais. Questão como transnacionalidade, cosmopolitanismo, coisas desse gênero.

5 Este é o nome da pesquisa orignal que gerou, entre outros trabalhos, o livro Culture, Class, Distinction. 
Então nós trabalhamos com a adequação de temas ao contexto e, de uma certa forma, com a adequação metodológica também, porque se pensarmos bem na maneira como A Distinção foi construída, no contexto inglês do momento em que a gente submeteu o projeto, a gente jamais teria obtido financiamento com a proposta metodológica do Bourdieu, entendeu?

A metodologia que nós oferecemos no CCSE é uma metodologia de métodos múltiplos, muito sólida. Nós começamos com uma série de vinte e cinco grupos focais analisando questões sobre as quais não havia muita literatura sociológica nos informando a respeito, como questões de desemprego, das vidas dos desempregados em certos locais do Reino Unido, sobre minorias étnicas. Categorias, que sociologicamente, não existia conhecimento acumulado para nós podermos intentificar num survey ou através de entrevista. Nós tínhamos que aprender sobre essas questões todas. Então nós fizemos grupos focais determinados em locais determinados com temas específicos que visavam preencher essas lacunas no nosso conhecimento. Não só da equipe, mas da sociologia naquele momento. A equipe era bem... conhecia muito bem a literatura sociológica daquele momento. Então nós fizemos os grupos focais, fizemos o questionário para o survey nacional, numa amostra representativa, entrevistando mil quinhentas e sessenta e quatro pessoas - entrevistamos mais, essa é a amostra que acabamos utilizando na análise.

O trabalho de campo demorou muito tempo, porque, primeiro, teve os grupos focais, depois teve o survey quantitativo e depois se seguiu um estudo qualitativo de domicílios, no qual também a gente fazia a observação do lar, do espaço, das pessoas, etc. Todos nós fizemos, todos os pesquisadores se envolveram nessa fase do trabalho. Nós também fizemos entrevistas com a elite. Só onze entrevistas porque é dificílimo fazer entrevista com elite. E sim, teve entrevista que foi feita em castelo, teve entrevista que foi feita nos altos bancos nas torres da city londrina, entendeu? Em casas de pessoas, escritórios, assim... e aí foi só a equipe central de quatro que fez essas entrevistas. Mas com tudo isso a gente cobriu um campo enorme para pensar as questões de classe e distinção social no mundo contemporâneo do Reino Unido de 2003 a 2006. E produzimos uma quantidade enorme de trabalhos. Nós escrevemos muito. Todos nós. Ao final erámos seis pesquisadores, porque os dois assistêntes de pesquisa, David Wright e Modesto Gayo-Cal se juntaram a nós excelentes colegas também - e nós publicamos muito individualmente, de dois a dois, três, quatro, cinco, seis, entendeu? Dependendo do tema, dependendo do interesse, e todo mundo escrevendo muito, pensando junto. 
O livro em si foi produzido absolutamente coletivamente. Nós usamos o estilo de produzir material didático da Open University, onde a gente (particularmente eu e Tony) sabia muito bem como trabalhar em grupo para produzir livro. Então a gente usou esse conhecimento pra produzir Culture, Class, Distinction. Na verdade cada um de nós éramos responsáveis por dois capítulos. Um era o "superresponsável" e o outro o "adjunto", tipo assim.

Michel Nicolau: Cada capítulo era feito por dois autores?

Elizabeth Silva: Dois autores eram responsáveis por cada capítulo. Um principal e o outro adjunto. E todo mundo lia todos os capítulos e comentava. A gente passava fins de semana, dois, três dias, só discutindo, quer dizer, tendo pré-circulado e tendo os comentários, só discutindo partes e encaminhávamos a produção escrita dessa forma. Realmente, foi um trabalho de fato coletivo, de fato feito conjuntamente e eu acho que o livro reflete isso, né? Você não vê, eu acho, as vozes das seis pessoas naquele livro, você vê a voz de um autor, ou de uma autora - eu sou a única mulher na equipe -, você vê uma voz, apenas. E claro, o trabalho tem imperfeições, a gente sabia que tinha. Tem coisas que, confessadamente, nós sabemos que gostarámos de ter feito melhor. Fizemos o melhor possível, com todo o conhecimento possível (...), a gente fez dez versões do questionário do survey antes de ir para campo, fizemos piloto e etc. A gente teve reuniões com os melhores acadêmicos especializados em questionários, survey, etc., no Reino, passávamos dias discutindo. Em termos de análise estatística a gente teve a felicidade de ter o apoio, a assistência, dos estatísticos que trabalharam com o Bourdieu em Distinção, Henri Rouanet e Brigite Le Roux. Infelizmente o Henri morreu durante a nossa pesquisa, a Brigite trabalhou até o final, e foi fundamental o trabalho que eles fizeram na análise de correspondência múltipla (ACM). Claro, [um trabalho] completamente diferente, porque Bourdieu e sua equipe tiveram que fazer com um papel transparente...

Michel Nicolau: Manteiga.

Elizabeth Silva: É! Manteiga. E um em cima do outro. Hoje em dia nós temos software, tem o SPAD e etc., e tudo aparece magicamente (risos), graças aos livros e as análises que Brigite e Henri escreveram, né?!

A gente fez análise de sete campos: do campo da música, do campo da literatura ou da leitura, do campo das artes visuais, do campo de filmes, do campo de esportes, do campo de práticas culinárias... Então isso também é um pouco diferente do que o Bourdieu fez. É uma das coisas que eu não mencionei antes. E através desse uso da análise de correspondências múltiplas nós fomos capazes de visualizar como 
o campo social é organizado em termos de um mapa cultural britânico, naquele momento. Então, se a gente vir esse mapa, do Reino Unido em 2003, que foi na época em que a gente fez o survey onde isso é baseado, a gente nota a homologia entre os campos, confirmando uma tese bourdiesiana, mas a gente vê que existem mais distinção em certos campos do que em outros. Por exemplo, os campos que distinguem menos são o campo da música e o campo da televisão. Mas os campos que mais distinguem são os campos, por exemplo, das artes visuais, e por aí afora. E aí a gente vê que têm muitas práticas também que aparecem no centro desse mapa cultural, o que quer dizer que [ali] falta distinção, que na verdade [ali] você não polariza. Então tem muita coisa que no mundo contemporâneo todo mundo faz.

Michel Nicolau: A prática de todo mundo.

Elizabeth Silva: Exatamente. É prática de todo mundo. Mas aí o que é interessante também - e aí [tem] uma tese muito legal, que é a tese do onivorismo - é que dentro de tudo o que todo mundo faz ainda aparecem distinções, certo? E aí você [entende que], dentro dessa tese do onivorismo que, "quem gosta de tudo não é todo mundo", entendeu $?^{6} \mathrm{Na}$ verdade, isso ainda, o gosto de tudo ainda é marcado por um gosto de elite, então tem uma marca de classe, né, até na não polarização e que é uma coisa sutil de se observar. Mas, ao invés do que o Bourdieu descobriu em Distinção (o gosto do empresário e o gosto do intelectual), o que a gente vai ver são interesses diferentes onde você tem o interesse pelo o que é mais estabelecido e o interesse pelas coisas comerciais também. Quer dizer, são contextos diferentes. Você tem que ver isso como coisas aparecendo de uma maneira nova, mas claro, a divisão de classe social está estabelecida, está marcada. Isso é visto, mas não se reflete da mesma forma. O que é importante para nós, e é o eixo principal da análise de correspondências múltiplas, é entre os que participam das formas dos itens culturais, das formas de cultura oferecida, e os que não participam, mas ao mesmo tempo a gente tem que problematizar a questão do engajamento. O que significa estar engajado? E o que significa estar desengajado de cultura? E aí tem os problemas de como o método reflete o que a gente acaba descobrindo porque de uma certa forma nós recriamos o mundo social num método que nós usamos que não conseguiu

\footnotetext{
6 A tese do onivorismo cultural foi cunhada por Richard Peterson a partir de estudos sobre o gosto musical nos Estados Unidos em uma série de textos publicados também com outros colaboradores. Centralmente, a tese defende que há uma passagem contemporânea de um gosto demarcado por fronteiras bem estabelecidas entre hierarquias de bens culturais, para um gosto marcado pelo ecletismo cultural, que atravessa tais fronteiras. É o caso de ter se tornado comum uma pessoa gostar ao mesmo tempo de jazz e funk. Para Peterson e seus colaboradores, contudo, o ecletismo cultural (o onivorismo) é marcado por diferenças sociais, uma vez que a elite cultural é muito mais propensa a ele do que as classes populares, essas mais propensas a um gosto unívoro, em oposição à elite. Como afirma Elizabeth Silva na entrevista, "quem gosta de tudo não é todo mundo". Ver textos de Peterson na bibliografia.
} 
captar muito da participação cultural no local, localizada. Então, de uma certa forma nós reproduzimos [a falta de observação detalhada das culturas locais], e é muito difícil você não fazer isso, mas eu acho que uma coisa que pesquisadores que fazem outros estudos hoje em dia têm que prestar atenção, mais do que nós prestamos, [é] na importância da cultura local. Mas aí como é que essa se reflete em termos de capital cultural, não é?

Michel Nicolau: Como é que ela atravessa a sociedade.

Elizabeth Silva: Extamente! Mas eu acho que é uma questão que tem que ser investigada. Que na verdade, capital cultural tem em si uma dose do estabelecido, do legitimado que é importante. Mas dentro do discurso de onivorismo e das formas comerciais - a participação na cultura comercial depende de capital econômico também, sem dúvida alguma - deve-se tentar reestabelecer essas relações sem esquecer e sem dar a etiqueta de desengajado para gente que está engajado com questões locais, culturais, de significância importante e que pode ter capital cultural que contextualmente tenha significados distintivos?

Michel Nicolau: Por exemplo: participação em concertos musicais em igrejas no Brasil. Em igrejas evangélicas isso é muito forte. Numa pesquisa em que você não coloca a igreja como um ambiente de participação isso desaparece, né?!

Elizabeth Silva: Interessante esse exemplo! Exato.

Michel Nicolau: E a partir do Culture, Class, Distinction, por exemplo, como você está colocando, a questão do habitus se mantém como uma categoria válida, mas, me parece, que é uma categoria que, a partir dessa pesquisa, você vai o tempo todo refinando. Quer dizer, a ideia de habitus como unidade fragmentada, a ideia de relação habitus e gênero ${ }^{8}$. Queria que você falasse um pouco como que isso acabou aparecendo nos desenvolvimentos subsequentes da sua pesquisa.

Elizabeth Silva: Uma das questões que eu e meus colegas nos mobilizamos bastante para fazer com relação a esse trabalho empírico [de Culture, Class, Distinction] foi

\footnotetext{
7 A maior parte dos estudos sobre participação cultural adota como índice a participação das pessoas em espaços estabelecidos de cultura (cinema, teatro, ópera, etc.). Aos que participam nesses espaços, dá-se o nome de engajados; aos que não, de desengajados, estabelecendo entre eles uma hierarquia. Elizabeth Silva nos alerta para algo fundamental. Ao não considerarmos práticas culturais locais (como ouvir música na Igreja, ir ao funk no bairro, etc.) os dados de pesquisa nos apresentam como desengajados culturalmente pessoas altamente engajadas em espaços não estabelecidos.

8 Faço referência a dois textos de Elizabeth Silva que seguem nessa direção. Ver na bibliografia (Silva, 2016 a e 2016 b).
} 
repensar as categorias principais da perspectiva bourdiesiana. Então na verdade, nós fizemos certas revisões de conceito de capital. Tem um special issue que o Tony Bennett e eu fizemos ${ }^{9}$; do conceito de campo que eu e o Mike Savage (Savage \& Silva, 2013) fizemos e do conceito de habitus que eu fiz sozinha num dossiê (Silva E. B., 2016b). E com o Alan eu fiz um livro sobre as perspectivas, as maneiras, que hoje em dia os acadêmicos lidam com a teoria bourdiesiana (Silva \& Warde, 2010). Então todos nós colaboramos em trabalhos de revisões teóricas importantes da teoria bourdiesiana no fundamental. Mas para trazer para questão do habitus, dentro do trabalho que nós fizemos no Culture, Class, Distinction, uma coisa que foi bastante frustrante na análise foi que gênero não aparece com a significância que nós imaginávamos que teria. E eu disse, eu mencionei que eu era a única mulher numa equipe de seis pessoas e os meus colegas tiveram enorme cuidado e sensibilidade quando eles vieram me dizer "Elizabeth, a análise de gênero não está demonstrando nada", porque eles sabiam, óbvio, do meu interesse teórico, empírico na questão de gênero era grande já há bastante tempo. Sim, e nós fizemos um capítulo sobre gênero em Culture, Class, Distinction. É um capítulo muito interresante, mas é um trabalho onde a análise de correspondências múltiplas não mostra muito. Mostra uma diferença muito grande entre homens e mulheres, mas de uma forma mais grosseira e o capítulo se beneficia bastante de análise qualitativa pra refinar e para fazer tudo o que fosse possível dentro da análise de gênero com o material que nós tinhámos. Mas eu permaneci muito insatisfeita com esse capítulo e com isso que a gente fez no Culture, Class, Distinction. Então, um ano, dois, mais tarde, eu convidei Brigite Le Roux para vir para Londres e nós nos trancamos na minha casa por dez dias, analisando dados estatísticos para ver o que é que a gente podia descobrir sobre gênero.

Michel Nicolau: Da pesquisa original?

Elizabeth Silva: Da pesquisa original. E, realmente, eu me lembro até agora do momento 'eureka' - pois teve um momento 'eureka' e foi fantástico! O que eu e Brigite fizemos foi: a gente recodificou muito do material, porque eu perguntava as questões e a Brigite tentava fazer a análises estatísticas e aí ela falava: "Eu preciso de mais disso, e aí como é que a gente faz?". Foi um processo muito interessante. E o que nós fizemos foi uma análise de idade. Na verdade, tipo de interseccionalidade. Gênero apenas, não conseguia mostrar, mas gênero com idade começou a mostrar diferenças interessantes, principalmente na vida de casais. Então, nós recodificamos da pesquisa qualitativa para recolocar dentro do survey, para ver as posições dos

9 Elizabeth Silva faz referência a uma edição especial da revista Poetics, que ela editou com Tony Bennett sob o título de Cultural Capital: Histories, Limits, Prospects (2011). 
indivíduos dentro dos estratos etários, e deu uma diferença significativa na qual as mulheres de idade entre 18-45 anos, principalmente 25-45, mas vai de 18-54; essas mulheres têm um envolvimento muito maior com a cultura legítima do que os homens e esta é a fase em que as mulheres estão, basicamente, responsáveis pela educação de filhos. As mulheres sabem que a cultura legítima conta muito mais em termos de mobilidade social para os filhos.

E a gente publicou um artigo, eu e a Brigite Le Roux, que se chama "The Cultural Capital of Couples", que publicamos em Poetics em 2011 (Silva \& Le Roux, 2011). E aí na minha revisão da noção de habitus tudo começou com uma pergunta "Onde é que está a psyche do habitus?". Na verdade eu organizei um evento da British Sociological Association, Psyche in the Habitus, em Londres, que foi muito interessante. Teve muita participação, foi ótimo e tal, e na verdade aí eu comecei a pensar na questão de como o Bourdieu tinha tratado a questão do habitus dentro da carreira dele e como é que hoje em dia a gente podia lidar com a questão do habitus. Porque, você veja, dentro do engajamento todo de Culture, Class, Distinction, de todo o projeto, do começo ao fim, uma preocupação muito grande é com a mudança social e o habitus não é uma categoria que é famosa por ajudar na compreensão de mudança social; pelo contrário, é uma categoria apresentada como sendo a categoria da reprodução; é a categoria da estabilidade, etc. Mas como é que você faz quando na verdade a influência da socialização não opera apenas verticalmente, dos pais, da origem, para o filho, e o que é que você faz com a socialização horizontal? O que é que você faz com a influência sua como meu amigo em mim, no que eu desejo para mim em termos da minha estética de vida, em termos das coisas que eu desejo, ou etc. Então você começa a pensar nisso e também na diferença que historicamente, temporalmente, a gente tem quando as pessoas existiam em espaços - existiam em termos de viver em espaços muito mais tradicionais e estáveis - e quando você vive num mundo social que está em extrema mudança.

\section{REFERÊNCIAS}

BENNETT, Tony; SILVA, Elizabeth Bortolaia. (orgs.). Cultural Capital: Histories, Limits, Prospects, Poetics (Vol. 39, issue 6), 2011.

BENNETT, Tony; EMMISON, Michael; FROW, John. Accounting for tastes: Australian Everyday Cultures. Cambridge: Cambridge University Press, 1999.

BENNETT, Tony; SAVAGE, Mike; SILVA, Elizabeth Bortolaia; WARDE, Alan; GAYOCAL, Modesto; WRIGHT, David. Culture, Class, Distinction. New York and London: Routledge, 2009. 
BOURDIEU, Pierre. A Distinção: crítica social do julgamento. Porto Alegre: Zouk, 2011. BOURDIEU, Pierre. Distinction: a social critique of the judgement of taste. London, New York: Routledge, 1984.

BOURDIEU, Pierre. La distinction: critique sociale du jugement. Paris: Les Éditions de Minuit, 1979.

COWAN, Ruth Schwartz. More Work for Mother: the ironies of household technology from the open hearth to the microwave. London: Free Association Books, 1989.

PETERSON, Richard. Understanding audience segmentation: From elite and popular to omnivore and univore. In: Poetics, v. 21, n. 4, p. 243-258, 1992.

PETERSON, Richard; KERN, Roger. Changing highbrow taste: From snob to omnivore. American Sociological Review, v. 61, n. 5, p. 900- 907, 1996.

PETERSON, Richard; SIMKUS, Albert. How Musical Taste Groups Mark Occupational Status Groups. In: Lamont, Michèle; Fournier, Marcel. Cultivating Differences: Symbolic Boundaries and the Making of Inequality. Chicago, IL: University of Chicago Press, pp. 152-68, 1992.

SAVAGE, Mike; SILVA, Elizabeth Bortolaia. Field Analysis in Cultural Sociology. Cultural Sociology, 111-126, 2013.

SILVA, Elizabeth Bortolaia. Refazendo a Fabrica Fordista. Constrastes ada Industrial Automobolistica no Brasil e na Gra-Bretanha. Sao Paulo: Hucitec/Fapesp, 1991.

SILVA, Elizabeth Bortolaia. Good Enogh Mothering?: Feminist Perspectives on Lone Motherhood. London: Routledge, 1996.

SILVA, Elizabeth Bortolaia. Unity and fragmentation of the habitus. The Sociological Review, 64, 166-183, 2016a.

SILVA, Elizabeth Bortolaia. Habitus: beyond sociology. The Sociological review, 64, 73-92, 2016b.

SILVA, Elizabeth Bortolaia. Technology, Culture, Family: Influences on Home Life. London: Palgrave, 2010.

SILVA, Elizabeth Bortolaia; SMART, Carol. The new family? London: Sage, 1999.

Silva, Elizabeth Bortolaia; Le Roux, Brigitte. Cultural capital of couples: tensions of elective affinities. Poetics, 39 (6), 547-565, 2011.

SILVA, Elizabeth Bortolaia; WARDE, Alan. Cultural Analysis and Bourdieu's Legacy: settling accounts and developing alternatives. New York: Routledge, 2010. 
